\title{
RNAi in the cereal weevil Sitophilus spp: Systemic gene knockdown in the bacteriome tissue
} Agnès Vallier ${ }^{1}$, Carole Vincent-Monégat ${ }^{1}$, Anne Laurençon ${ }^{2}$ and Abdelaziz Heddi*1

Address: ${ }^{1}$ Université de Lyon, INRA, INSA-Lyon, IFR-41, UMR203 BF2I, Biologie Fonctionnelle Insectes et Interactions, 20 ave A Einstein, F-69621 Villeurbanne, France and 'Université de Lyon, Lyon, F-69003, France, Université Lyon 1, CNRS, UMR5534, Centre de Génétique Moléculaire et Cellulaire, Villeurbanne, F-69622, France

Email: Agnès Vallier - agnes.vallier@insa-lyon.fr; Carole Vincent-Monégat - carole.monegat@insa-lyon.fr; Anne Laurençon - laurencon@cgmc.univ-lyon1.fr; Abdelaziz Heddi* - Abdelaziz.Heddi@insa-lyon.fr

* Corresponding author

Published: 15 May 2009

BMC Biotechnology 2009, 9:44 doi:10.1/86/1472-6750-9-44
Received: 8 February 2009

Accepted: 15 May 2009

This article is available from: http://www.biomedcentral.com/I472-6750/9/44

(c) 2009 Vallier et al; licensee BioMed Central Ltd.

This is an Open Access article distributed under the terms of the Creative Commons Attribution License (http://creativecommons.org/licenses/by/2.0), which permits unrestricted use, distribution, and reproduction in any medium, provided the original work is properly cited.

\begin{abstract}
Background: The weevils Sitophilus spp. are among the most important cosmopolitan pests of stored cereal grains. However, their biology and physiology are poorly understood, mainly because the insect developmental stages take place within cereal grains and because of the lack of gene specific molecular manipulation.

Results: To gain access to the different insect developmental stages, weevil females were allowed to lay their eggs on starch pellets and hatched embryos were collected by dissolving starch with water. Embryos were transferred between two Glass Plates filled with packed Flour (GPF) to mimic compact texture of the cereal grain, and this system allowed us to recover specific developmental stages. To knockdown the gene expressed in the bacteria-bearing organ (the bacteriome), whole larvae were injected with dsRNA to target the wpgrp / gene and they were then left to develop for a further 4 days period. Quantitative RT-PCR and Western blot analyses on the bacteriome of these animals revealed a down-regulation of the wpgrp / expression, both at transcript and protein levels.

Conclusion: These results demonstrate that whole larval injection with dsRNA results in a high and systemic decrease of both mRNA and protein in the bacteriome tissue. This, along with the possibility of access to the insect developmental stages, opens up a new research avenue for exploring gene specific functions in the cereal weevils.
\end{abstract}

\section{Background}

Cereals are the world's basic staple food and they provide an energy and protein source for many populations, particularly in the developing world. Unfortunately, cereal grain losses during storage can reach up to $50 \%$ of the total harvest in some countries, which represents a world- wide loss equivalent to thousands of millions of euros [1]. Grain weevils Sitophilus spp. (Dryophthoridae, Curculionoidea) are well-known as major primary pests of stored cereal grains causing damage and rendering the grain more susceptible to attack by secondary insect pests such as Tribolium. 
The genus Sitophilus includes three cereal feeding species (Sitophilus oryzae, Sitophilus zeamais and Sitophilus granarius). Interestingly, all three species share an intracellular symbiosis with a Gram-negative $\gamma$-Proteobacterium $[2,3]$. Symbiotic bacteria (endosymbionts) are transmitted maternally to the offsprings and, at an early stage of host embryogenesis, these bacteria induce the differentiation of specialized host cells (the bacteriocytes) that house the bacteria, protect them from the host immune system $[4,5]$, and form a symbiotic organ (the bacteriome) that persists throughout the larval stages [6]. Endosymbiotic bacteria balance the insect diet within the cereal grains, which are starch-rich but poor in amino acids, lipids and vitamins [7-9]. This improves mitochondrial energetic metabolism and impacts, thereby, on the insect fitness, flight ability and invasive power $[10,11,6,12]$.

The control of these storage insects is mainly mediated by use of synthetic insecticides, which generate high environmental costs and lead to insecticide resistant strains [13]. Consequently the development of methods facilitating molecular manipulation of these insects is of wide interest. As insect physiology and reproduction are drastically disturbed in the absence of endosymbionts, one innovative strategy would rely on a better understanding of host symbiont interaction.

Sequencing of the Sitophilus endosymbiont genome, along with the development of expressed sequence tags helps to the better knowledge of the weevil biology and physiology $[14,4,15]$. One very promising method for generating targeted down-regulation of gene expression in a wide range of organisms is RNA interference (RNAi) [16]. RNAi also has evolved into a powerful tool for probing gene function in Drosophila, Tribolium, Caenorhabditis elegans and mice. Delivery of dsRNA or siRNA into a cell triggers abrogation of the target mRNA. Previous experiments have shown the feasibility of using RNAi to abrogate the expression of gene transcripts in several insects [17].

A number of animal cells have been shown to naturally take up exogenous dsRNA and use it to initiate RNAi silencing. In some organisms, such as Drosophila and Bombyx mori, certain cells show an efficient uptake of dsRNA but they seem to be unable to transmit this dsRNA to other cells in the body $[17,18]$. Organisms, such as C. elegans, can both take up dsRNA and spread it systemically to elicit an RNAi response throughout the entire organism. Interestingly, the first systemic RNAi response in insects was documented in the flour beetle Tribolium castaneum: an injection of dsRNA into the larvae results in specific gene silencing in adults [19]. This effect can also be transmissible between generations [20]. This coleopteran spe- cies is closely related to Sitophilus both phylogenetically and ecologically.

We thus undertook research to access the biological and physiological aspects of the Sitophilus system based on the use of genomic tools. The weevil lifestyle and behavior limits embryonic, larval and nymphal development to within the grain only. Thus, weevils cannot survive or reproduce on cereal flour in the way that Tribolium insects do. Here, we present new rearing conditions that allow experimental access to different embryonic and larval stages of the cereal weevil Sitophilus. This system enables us to keep insects alive outside the cereal grains for the whole life cycle. To test the protocols for gene silencing in Sitophilus we have selected a gene specifically expressed in the bacteriome, which encodes the peptidoglycan recognition protein (wpgrp1) [21,4]. Using injected dsRNA, we present evidence of systemic RNAi in the weevil Sitophilus spp.

\section{Methods \\ Insect rearing}

Insects from Sitophilus zeamais species (Lagoa strain) were reared as described in [21]. Larvae normally grow inside the wheat grains until they emerge as adults one month after the egg laying, at $27.5^{\circ} \mathrm{C}$ and $70 \%$ relative humidity (rh). For RNAi experiments, third-instar larvae were dissected out of the grains and kept alive in a moist atmosphere at $27.5^{\circ} \mathrm{C}$ for the length of the experiment.

\section{Using Glass Plates filled with packed Flour (GPF) for artificial rearing}

Normally cereal weevil larvae fail to feed outside the grains for behavioral reasons. To overcome this barrier, we have set up an artificial system to mimic the compactness of the cereal grain, which consists of filling with wheat flour the space between two glass plates separated with $1.5 \mathrm{~mm}$-thick spacers (figure 1). Weevil individuals (larvae or embryos) are deposited between two layers of packed wheat flour. We first deposit the first flour layer between the glass plates, then the lavae, and finally we recover the larvae with a second flour layer. This system could also be adapted in an Eppendorf tube.

To access the insect embryonic and post-embryonic stages, both embryos and third-instar larvae were raised within the GPF and kept at $27.5^{\circ} \mathrm{C}$ and $70 \%$ rh until the adults emerged. Females were allowed to lay eggs on starch pellets (L'amidon Remy, ADS) over a period of 4 hours and the embryos were collected by dissolving the starch in water. Embryos were transferred immediately into the GPF system and left in an incubator until the adults emerged. Third-instar larvae were removed directly from the wheat grains after dissection. 


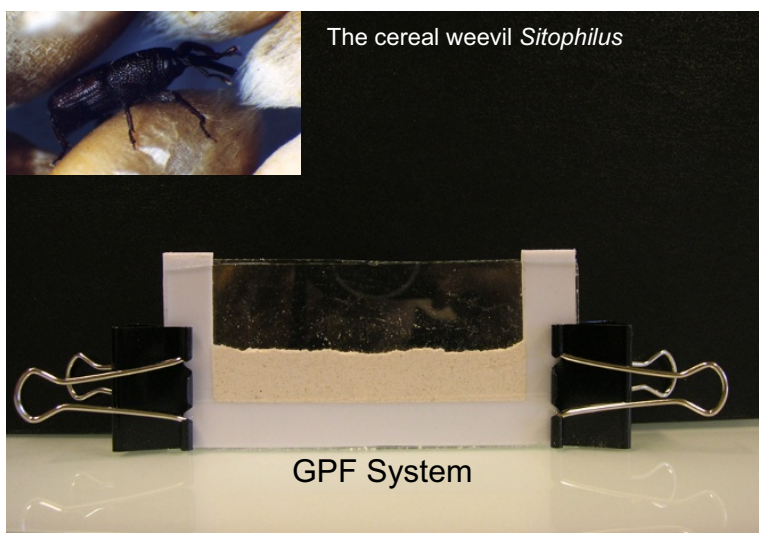

\section{Figure I}

Glass Plates filled with packed Flour (GPF). This artificial system aims to mimic the compactness of the cereal grain. It consists of filling the space between two glass plates, separated with $1.5 \mathrm{~mm}$-thick spacers, with wheat flour. Weevils are individually deposited between two layers of packed wheat flour and transferred to the incubator $\left(27.5^{\circ} \mathrm{C}\right.$ and $70 \%$ relative humidity). This protocol could be adapted to an Eppendorf vial system.

\section{dsRNA synthesis and injection}

The method used to synthesize dsRNA is similar to that described by [22]. The primers were designed with the software E-RNAi, available at http://www.dkfz.de/ signaling2/e-rnai/. For the wpgrp1 gene, we used the primers 5'wpgrp1-T7dsRNA and 3'wpgrp1-T7dsRNA that match within the coding sequence, and for the gfp gene we used the primers 5 'gfp-T7dsRNA and 3 'gfp-T7dsRNA (see Table 1). The nucleotides in bold are from the T7 RNA polymerase promoter.
Recombinant plasmids pCR2.1-topo-wpgrp1 [21] and pw8-gfp [23] were used as a matrix to amplify, respectively, wpgrp1 and $g f p$ with BD Advantage 2 polymerase Mix (BD Biosciences). PCR products were cleaned with a NucleoSpin Extract II kit (MachereyNagel) and were used as templates for in vitro dsRNA synthesis using a MEGAscript RNAi Kit (Ambion, Austin, TX). After synthesis, the dsRNA was precipitated overnight at $-80^{\circ} \mathrm{C}$ with $0.3 \mathrm{M}$ sodium acetate, $1.5 \mu \mathrm{l}$ glycogen and 2 volumes of $100 \%$ ethanol, resuspended in water to a final concentration of $2.89 \mu \mathrm{g} / \mu \mathrm{l}$. The purity and the integrity were determined by Nanodrop and agarose gel electrophoresis. The RNA was kept at $-20^{\circ} \mathrm{C}$ prior to injection within the following 7 days.

$200 \mathrm{ng}$ of dsRNA ( $69 \mathrm{nl}$ ) were injected into the dorsal and posterior part of third-instar larvae using the Nanoinject II nanoinjector (Drummond scientific) and they were kept in the GPF system for 4 days. Bacteriomes were subsequently isolated for RNA extraction.

\section{Total RNA extraction and cDNA synthesis}

Bacteriomes were dissected (25 for each RNA sample) from the fourth instar larvae and total RNA was extracted by RNAqueous ${ }^{\circledast}$-Micro (Ambion), a micro-scale RNA isolation kit, as described in the manufacturers' procedure that includes a DNase treatment final step. After purification, the RNA concentration of each sample was measured by the Nanodrop ${ }^{\circledast}$ spectrophotometer and total RNA quality was checked by electrophoresis. Reverse-transcription into the first strand cDNA was carried out using the First strand Synthesis System for RT-PCR kit (Invitrogen).

\section{Real-time RT PCR transcript quantification}

Quantitative measurements were performed on RNA samples originating from 5 independent replicates. The quantification was performed with a LightCycler ${ }^{\circledast}$ instrument using the LightCycler Fast Start DNA Master SYBR green I

Table I: Primer sequences used for dsRNA synthesis, Reat-time RT PCR and wpgrp I cDNA amlification. The nucleotide in bold are from the T7 RNA polymerase promoter.

\begin{tabular}{ll}
\hline Primers used for dsRNA synthesis \\
5'pgrpl-T7dsRNA & 5'-TAATACGACTCACTATAGGGCCAGTCCCTTACGTCGTCAT-3' \\
3'pgrpl-T7dsRNA & 5'-TAATACGACTCACTATAGGGTCTGTTTCTCGGACTTGCCT-3' \\
5'gfp-T7dsRNA 5' & 5'-TAATACGACTCACTATAGGGCAAGGAGGACGGCAACATCC-3' \\
3'gfp-T7dsRNA & 5'TAATACGACTCACTATAGGGATTTTATGTTTCAGGTTCAG-3'
\end{tabular}

Primers used for Real-time RT PCR transcript amplification wpgrpl-For 5'-ATAATTTCGCTGTTGGAGGG-3'

wpgrpl-Rev 5'-TCTCGGACTTGCCTATGACC-3'

gapdh-For 5'-AACTTTGCCGACAGCCTTGG-3'

gapdh-Rev 5'-GCGCCCATGTATGTAGTTGG-3'

Primers uses for PCR amplification of wpgrpI cDNA

For-wpgrpl cDNA 5'-ATGTCCAGTAAGCAATCACGG-3'

Rev-wpgrpI cDNA 5'-TAACACAATTAGAGTGAAAGATAG-3' 
kit (Roche Diagnostics). Data were normalized using the ratio of the target CDNA concentration to that of the glyceraldehyde 3-phosphate dehydrogenase (gapdh) gene. The expression of this gene is not significantly influenced by the treatments and it is similar to the expression of the ribosomal protein L29 gene (data not shown). Primers were designed to amplify fragments with less than $300 \mathrm{bp}$; wpgrp1-For and wpgrp1-Rev generate a wpgrp1 fragment of $248 \mathrm{bp}$ in length, and gapdh-For and gapdh-Rev generate a gapdh fragment of $277 \mathrm{bp}$ in length (Table 1).

The PCR reactions were carried out in LightCycler 96-well plates in a final volume of $10 \mu \mathrm{l}$ containing $2.5 \mu \mathrm{l}$ of cDNA samples (diluted fivefold) and $7.5 \mu \mathrm{l}$ of Light Cycler ${ }^{\circledR} 480$ SYBR Green Master $1 \mathrm{mix}$, with $0.5 \mu \mathrm{l}$ of $10 \mathrm{mM}$ of each primer, $1.5 \mu \mathrm{l} \mathrm{H} 2 \mathrm{O}$ and $5 \mu \mathrm{l}$ of Mastermix. After $5 \mathrm{~min}$ at $95^{\circ} \mathrm{C}$, the cycling conditions were as follows: 45 cycles at $95^{\circ} \mathrm{C}$ for $10 \mathrm{~s}, 56^{\circ} \mathrm{C}$ for $20 \mathrm{~s}$ and $72^{\circ} \mathrm{C}$ for $30 \mathrm{~s}$. For product identification, a melting curve was constructed at the end of each PCR by heating for $30 \mathrm{~s}$ at $66^{\circ} \mathrm{C}$ and then increasing the temperature up to $95^{\circ} \mathrm{C}$ with increment rates of $0.11^{\circ} \mathrm{C} / \mathrm{s}$. Reactions were achieved by cooling at $40^{\circ} \mathrm{C}$ for $30 \mathrm{~s}$.

The PCR efficiency (The efficienty (E) is calculated from the slope of the standard curve, which is obtained with

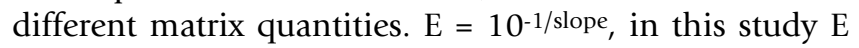
was $97.7 \%$ for the gapdh and $94.4 \%$ for the wpgrp1) and, for the individual samples, the crossing point $(\mathrm{Cp}$, the point at which amplified product is first visible in the data) and the concentration (conc.) of the wpgrp1 (or the gapdh) transcripts were determined. As the quantification relies on the PCR efficiency of each experiment, ratios were then normalized with the gapdh. The relative ratio for each sample was calculated according to the formula: (conc. wpgrp1 (sample)/conc. gapdh (sample)). Normalized data were analyzed using the one-way ANOVA and Tukey HSD post hoc test [24].

\section{Expression of recombinant Protein in Escherichia coli for antibody preparation}

Total cDNA from larval bacteriomes of Sitophilus zeamais served as a template in PCR amplification for isolating the wpgrp1 cDNA.
The primers used were For-wpgrp1 cDNA and Rev-wpgrp1 cDNA (Table 1). The resulting DNA encoded 263 residues of the mature protein. The PCR product $(789 \mathrm{pb})$ was cloned into a pTrc-His-Topo expression vector (Invitrogen) and the resulting vector was introduced into an E. coli TOP10 strain. The nucleotide sequence of the synthesized gene was checked by dideoxynucleotide sequencing and the recombinant plasmid was transformed into the E. coli BL21 strain. Expression of the recombinant protein Wpgrp1 flanked with 6 histidines at N-terminus was induced by $1 \mathrm{mM}$ isopropyl-D-thiogalactopyranoside at an optical density of 0.6 at $30^{\circ} \mathrm{C}$ for 4 hours.

Bacterial lysates were prepared by sonication in buffer A, pH 8 containing $50 \mathrm{mM}$ sodium phosphate, $300 \mathrm{mM}$ $\mathrm{NaCl}$ and lysozyme to a final concentration of $1 \mathrm{mg} / \mathrm{ml}$. The fusion protein bound to a Protino-Ni column (Macherey-nagel) was eluted with buffer A containing $250 \mathrm{mM}$ imidazole after the column had been washed with buffer A. The eluted fraction was dialyzed against buffer containing $0.05 \mathrm{M}$ Tris-HCl (pH 8.8), 1 mM EDTA and 10\% glycerol. The protein was mixed with $2 \times$ SDS loading buffer and then, separated by electrophoresis in a $12.5 \%$ acrylamide gel. Next, the protein band was cut, N-terminal sequenced, and sliced into pieces for injection into rabbit to generate polyclonal Wpgrp1 antiserum at CovalAb Lyon (France), which was harvested 74 days after the initial inoculation.

\section{Western-blot analysis}

Western blot analysis was performed using an enhanced chemiluminescence (ECL) western blotting analysis system (Amersham Biosciences, Piscataway, NJ, USA). The protein samples from the bacteriome were mixed with the sample buffer, boiled for $5 \mathrm{~min}$, and loaded onto a $12.5 \%$ SDS-PAGE. The proteins were blotted onto a sheet of PVDF membrane (Amersham). After blotting, the membrane was blocked by incubation in a $3 \%$ gelatin solution, incubated with anti-wpgrp1 antiserum solution (1:500 v/ $\mathrm{v})$ at room temperature for $2 \mathrm{~h}$ and washed in TBST (100 $\mathrm{mM}$ Tris- $\mathrm{HCl}, \mathrm{pH} 8,100 \mathrm{mM} \mathrm{NaCl}, 0.1 \%$ Tween 20$)$. For normalization, blots were probed with a $\beta$-tubulin antibody raised from the Drosophila melanogaster $\beta$-tubulin (tebu-bio, 1:500 v/v). The membrane was then incubated with 1:5000 (v/v) diluted anti-rabbit IgG-peroxydase anti-

Table 2: Percentage of adult emergence of weevil embryos raised within GPF

\begin{tabular}{lccc}
\hline & Number of embryos per experiment & \% of adult emergence & Development time (days)* $^{*}$ \\
\hline Experiment I & 41 & 34.1 & 37 \\
Experiment 2 & 38 & 36.8 & 38 \\
Experiment 3 & 42 & 33.9 & 38 \\
Average & & 33.9 & $37.7 \pm 0.74$ \\
\hline
\end{tabular}

* The natural development time from the embryo to the adult of symbiotic weevils (at $27.5^{\circ} \mathrm{C}$ and $70 \mathrm{rh}$ ) is arround 30 days. 

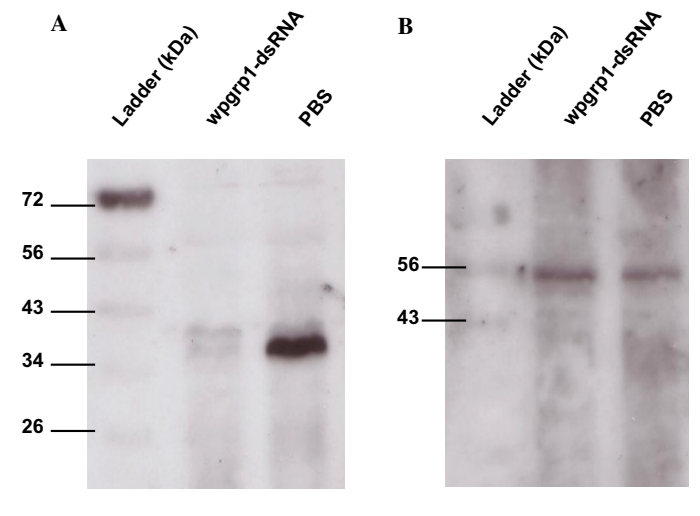

Figure 2

Western blot analysis of Wpgrp I protein steadystate levels in the bacteriome tissue four days after larval treatment. Injection of gfp-dsRNA gave a similar result to the PBS-treatment (data not shown). A and B are blots probed with anti-Wpgrpl and anti-tubulin antibodies, respectively. body produced in goat (Sigma). After repeated washing, the membrane was incubated with ECL detection reagents (Amersham Biosciences) and exposed to a film.

\section{Results and Discussion}

In this paper, we have first developed a new protocol to allow artificial rearing of weevils with access to the different stages of development and, secondly, we have demonstrated that RNAi technology can be applied to inhibit gene expression.

\section{Applying an artificial rearing methodology for weevil manipulation}

Unlike Tribolium, weevil larvae are unable to feed on wheat flour or to survive outside cereal grains for behavioral and morphological reasons. Larvae require a compact texture that applies pressure on their back, which is required for an access to the food with their mandibles. To mimic this structure, we have set up an artificial rearing apparatus that consists of depositing weevil embryos and larvae between two layers of packed wheat flour (see Fig. 1). To access the later stages of the weevil life cycle (i.e. third and fourth larval stages), larvae were directly har-

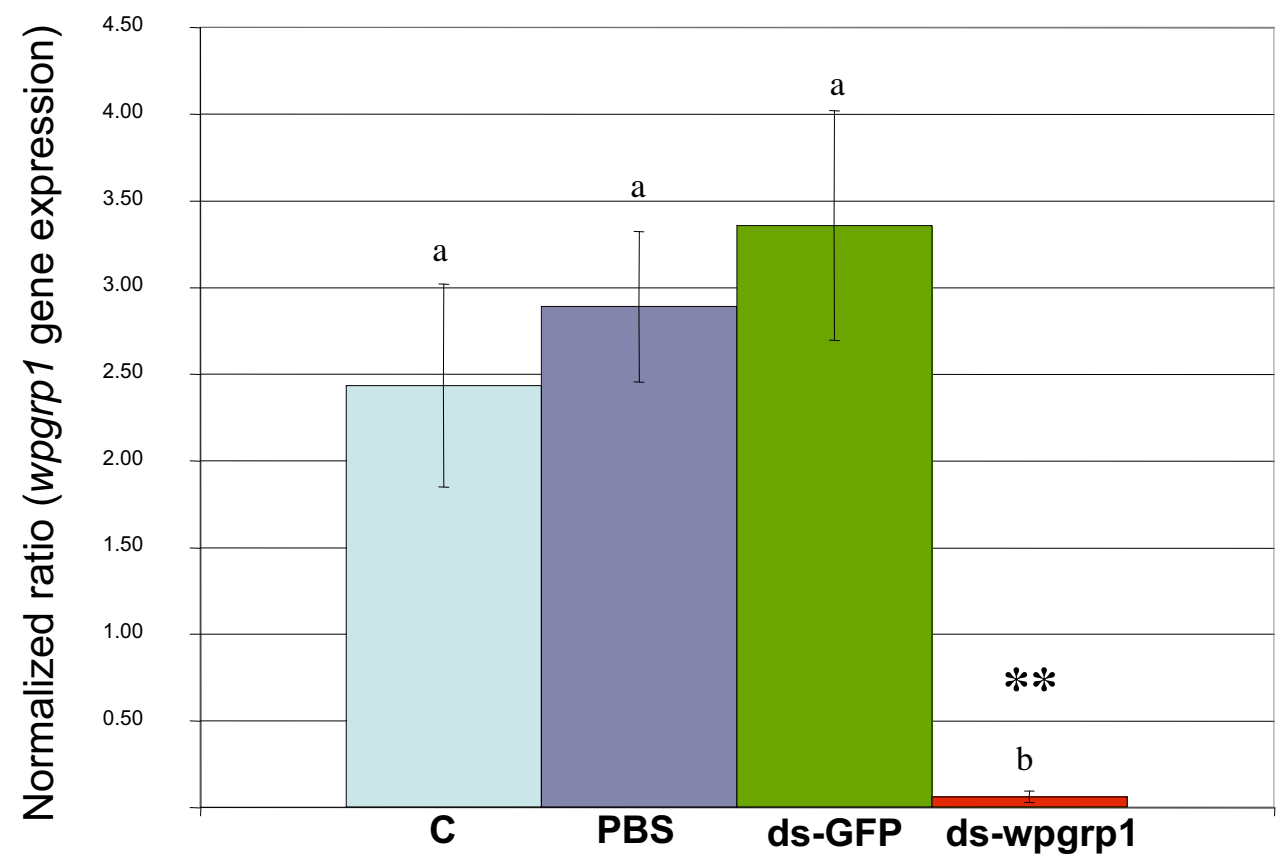

\section{Figure 3}

Q-RT PCR analysis of wpgrp I transcripts isolated from bacteriome tissues taken from fourth instar larvae four days after the treatments. C, are untreated control larvae; PBS, ds-gfp and ds-wpgrpI are larvae injected with PBS, gfpdsRNA and wpgrpI-dsRNA, respectively. Data are normalized with the gapdh transcript levels, expressed as means of 5 independent repetitions and analyzed with one-way ANOVA and Tukey HSD post hoc test. The asterisks show significant differences $(p<0.05)$. 
vested from grain dissection. Early development is accessible using the embryo stages recovered from 2- to 4-hr layings on starch kernels. Embryos are collected once the females have laid by dissolving starch in water. They can either be manipulated or transferred to the GPF system to obtain the later developmental stages. Survival rates presented in Table 2 show that up to $34 \%$ of embryos succeeded in reaching the adult stage. When larvae are transferred and raised in the GPF, the yield is close to $100 \%$ (data not shown).

This system is of interest to applied and fundamental sciences as it allows easy access to different stages. Drugs and molecules of interest could be mixed with the flour and, thus, be tested directly on the insect variants.

\section{Testing RNAi-mediated gene silencing in Sitophilus}

RNAi was tested on Sitophilus insects with the wpgrp1 gene as a target. We recently identified the wpgrp1 gene by suppression subtractive hybridization while screening for genes, which expression is upregulated in the bacteriome tissue [14]. To investigate the wpgrp1 function in more detail, we have raised a Wpgrp1 polyclonal antibody and we have confirmed the presence of a high amount of wpgrp1 protein within the bacteriome by Western blot analysis (Fig. 2).

When third instar larvae were injected with sterile PBS or with $g f p \_d s R N A$, the wpgrp1 transcript level in the bacteriome was within the same range as in the bacteriome of the uninjected control larvae. However, an injection of $200 \mathrm{ng}$ of wpgrp1_dsRNA in the larval hemolymph leads to a $98 \%$ reduction in the target gene, compared to $g f p \_d s R N A$ control in the bacteriome wpgrp1 transcript levels (Fig. 3). Furthermore, this downregulation at the transcript level also affects the amount of Wpgrp1 protein in the bacteriome (Fig. 2). These data highlight the efficiency of RNAi gene silencing in Sitophilus insects and show that the RNAi technique can be successfully used to knockdown target genes in the bacteriome tissue.

\section{Conclusion}

RNAi is a method by which dsRNA can be introduced directly into animals to trigger significant suppression of specific gene expression. In the light of our data, establishing the systemic RNAi pathway in this cereal weevil paves the way for more detailed comprehensive studies, on a molecularly level of weevil biology. The systemic RNAi pathway may also provide opportunities for developing species-specific, and, hence, ecologically friendly pest control methods. Genomic approaches have recently provided 10,000 unigenes, which will help to develop genome-wide RNAi applications addressing fundamental questions in cereal weevil physiology, development and gene regulation.

\section{Authors' contributions}

AV established and performed GPF system and RNAi experiments, performed Q-RT PCR; CVM expressed the wpgr1 protein and performed Western blot analysis; $\mathrm{AL}$ contributed in the RNAi experiments; $\mathrm{AH}$ conceived the work; All the authors contributed to the manuscript writing.

\section{Acknowledgements}

We gratefully acknowledge G. Reeck for his technical advice, M.O. Fauvarque and E. Bergeret for their technical support, E. Cortier for capillaries supply, A. Vigneron for statistics analysis, V. James for English corrections. The authors would also like to thank the anonymous reviewers for their constructive criticisms. This work was supported by the IFR4I (Institut Fédératif de Recherche Bio Environnement et Santé) and by the French ANR-06-BLAN-0316 (EndoSymArt).

\section{References}

I. Haff RPSD: Real-time X-ray inspection of wheat for infestation by the granary weevil. Sitophilus granarius (L.). Transactions of the ASAE 2004, 47:53I-537.

2. Heddi A, Charles H, Khatchadourian C, Bonnot G, Nardon P: Molecular characterization of the principal symbiotic bacteria of the weevil Sitophilus oryzae: A peculiar $\mathbf{G}-\mathbf{C}$ content of an endocytobiotic DNA. J Mol Evol 1998, 47(I):52-6I.

3. Charles $H$, Heddi A, Rahbé $Y$ : A putative insect intracellular endosymbiont stem clade, within the Enterobacteriaceae, infered from phylogenetic analysis based on a heterogeneous model of DNA evolution. C $R$ Acad Sci Paris 200I, 324:489-494.

4. Anselme C, Perez-Brocal V, Vallier A, Vincent-Monegat C, Charif D, Latorre A, Moya A, Heddi A: Identification of the weevil immune genes and their expression in the bacteriome tissue. $B M C$ Biol 2008, 6:43.

5. Reynolds S, Rolff J: Immune function keeps endosymbionts under control. J Biol 2008, 7(8):28.

6. Heddi A, Grenier AM, Khatchadourian C, Charles H, Nardon P: Four intracellular genomes direct weevil biology: Nuclear, mitochondrial, principal endosymbionts, and Wolbachia. Proc Natl Acad Sci USA 1999, 96:6814-6819.

7. Wicker C: Differential vitamin and choline requirements of symbiotic and aposymbiotic Sitophilus oryzae (Coleoptera: Curculionidae). Comp Biochem physiol 1983, 76A:177-I82.

8. Wicker C, Guillaud J, Bonnot G: Comparative composition of free, peptide and protein amino acids in symbiotic and aposymbiotic Sitophilus oryzae (Coleoptera, Curculionidae). Insect Biochem 1985, I 5(4):537-54I.

9. Nardon $P$, Grenier AM: Genetical and biochemical interactions between the host and its endosymbiotes in the weevil Sitophilus (Coleoptera Curculionidae) and other related species. In Cell to cell signals in plant, animal and microbial symbiosis Edited by: Scannerini S, et al. Springer-verlag Berlin; 1988:255-270.

10. Heddi A, Lefebvre F, Nardon P: Effect of endocytobiotic bacteria on mitochondrial enzymatic activities in the weevil Sitophilus oryzae (Coleoptera, Curculionidae). Insect Biochem Mol Biol 1993, 23:403-4II.

II. Grenier AMNP, Nardon C: The role of symbiotes in flight activity of Sitophilus weevils. Entomologia Experimentalis et Applicata 1994, 70:201-208.

12. Heddi A, Nardon P: Sitophilus oryzae L.: A model for intracellular symbiosis in the Dryophthoridae weevils (Coleoptera). Symbiosis 2005, 39: I-II.

13. Sighamony SAI, Chandrakala TS, Kaiser J: Indigenous plant products as grain protectants against Sitophilus oryzae (L) and Rhyzopertha dominica (F). J Stored Product Research 1990, 22:2I-23.

14. Heddi A, Vallier A, Anselme C, Xin H, Rahbe Y, Wackers F: Molecular and cellular profiles of insect bacteriocytes: mutualism and harm at the initial evolutionary step of symbiogenesis. Cell Microbiol 2005, 7(2):293-305. 
15. Gil R, Belda E, Gosalbes MJ, Delaye L, Vallier A, Vincent-Monegat C, Heddi A, Silva FJ, Moya A, Latorre A: Massive presence of insertion sequences in the genome of SOPE, the primary endosymbiont of the rice weevil Sitophilus oryzae. Int Microbiol 2008, II (I):4I-48.

16. Fire A, Xu S, Montgomery MK, Kostas SA, Driver SE, Mello CC: Potent and specific genetic interference by double-stranded RNA in Caenorhabditis elegans. Nature 1998, 39 I (6669):806-8II.

17. Price DR, Gatehouse JA: RNAi-mediated crop protection against insects. Trends Biotechnol 2008, 26(7):393-400. Epub 2008 May 2022

18. Marcus JM: Jumping genes and AFLP maps: transforming lepidopteran color pattern genetics. Evol Dev 2005, 7(2): 108-II4.

19. Tomoyasu Y, Denell RE: Larval RNAi in Tribolium (Coleoptera) for analyzing adult development. Dev Genes Evol 2004, 2 I 4(I I):575-578. Epub 2004 Sep 2009

20. Bucher G, Scholten J, Klingler M: Parental RNAi in Tribolium (Coleoptera). Curr Biol 2002, I 2(3):R85-86.

21. Anselme C, Vallier A, Balmand S, Fauvarque MO, Heddi A: Host PGRP gene expression and bacterial release in endosymbiosis of the weevil Sitophilus zeamais. Appl Environ Microbiol 2006, 72(10):6766-6772.

22. Goto A, Blandin S, Royet J, Reichhart JM, Levashina EA: Silencing of Toll pathway components by direct injection of doublestranded RNA into Drosophila adult flies. Nucleic Acids Res 2003, 3 I (22):6619-6623.

23. Loppin B, Lepetit D, Dorus S, Couble P, Karr TL: Origin and neofunctionalization of a Drosophila paternal effect gene essential for zygote viability. Curr Biol 2005, 15(2):87-93.

24. Team RDC: R: A language and environment for statistical computing. R Foundation for Statistical Computing. Vienna, Austria 2005 [http://www.R-project.org].

Publish with Bio Med Central and every scientist can read your work free of charge

"BioMed Central will be the most significant development for disseminating the results of biomedical research in our lifetime. "

Sir Paul Nurse, Cancer Research UK

Your research papers will be:

- available free of charge to the entire biomedical community

- peer reviewed and published immediately upon acceptance

- cited in PubMed and archived on PubMed Central

- yours - you keep the copyright 